\title{
A Pilot Study on Burnout Syndrome: Its existence, causes and coping strategies practiced by medical professionals in Colombo South Teaching Hospital, Sri Lanka
}

\author{
Manodya Kathriarachchi, \\ Postgraduate Student, \\ Buckinghamshire New University, UK \\ and \\ Gail Rowntree \\ Senior Lecturer \\ Buckinghamshire New University, $U K$
}

\begin{abstract}
Burnout syndrome among doctors causes increased turnover, decreased job satisfaction, depression, anxiety, frequent medical errors and patient death. Main aim of this paper is to identify existence of the burnout syndrome, underlying causes and analyze the coping strategies practiced by medical professionals of the Teaching Hospital, Colombo South (CSTH).

The review of definitions elaborated the most accepted definition of the syndrome as one consisting of three dimensions namely emotional exhaustion (EE), depersonalization (DP) and reduced personal accomplishment (PA). Individuals scoring positive on EE and/ or DP dimension regardless of scoring positive on all three dimensions of the syndrome are considered as undergoing burnout syndrome related to work. Method used for investigating burnout syndrome was a deductive approach with a quantitative survey strategy. The survey hosted three questionnaires. First questionnaire was self-administered and validated by the authors and attempted to identify the causative factors of the syndrome. Instrument 2 - MBI-HSS validated by Samaranayake and Seneviratne (2010) was used to assess the prevalence of the syndrome among medical professionals practicing at CSTH. Coping strategies questionnaire developed and validated by Ellawala (2010) was used to measure the strategies currently practiced among medical professionals. Data collection through surveys was conducted among a sample of randomly selected 100 medical professionals.
\end{abstract}

Findings illustrate that workload depicted in terms of private practice; gender and high personal contact nature of the work are not associated causes of the burnout syndrome. Long work hours, heavy work load, marital status, having less time to spend with family / friends, unpleasant work environment, unpleasant relationships with colleagues, having low autonomy at work and risk of major failure or patient death were recognized as associated causes of the burnout syndrome. Proportion of the syndrome was 53\%. Of the study sample, 30\% individuals scored positive on EE dimension, 24\% scored positive on DP dimension and 24\% scored positive on PA dimension. When considering the most popular coping strategies practiced in stressful situations, it was reported that listening to music, obtaining emotional support from family / friends and seeking comfort in the religion respectively. Another finding that contrasts from the major studies illustrated that $92 \%$ of the medical professionals in the sample never practiced harmful coping strategy of substance abuse for mitigating stress. 
Key Words: Burnout syndrome, Emotional exhaustion, Depersonalization, Reduced personal accomplishment, Medical professionals, Occupational stress, Coping strategies

\section{Introduction}

Healthcare sector in Sri Lanka has drastically risen above the regional averages (Alwis \& Christopher, 2014). The government spending for healthcare in Sri Lanka stands for a high of LKR 125 billion in 2014 (Alwis \& Christopher, 2014). A total of 17,271 doctors were employed in 2013 and another 14,931 nurses during the same year (Alwis \& Christopher, 2014).

Colombo South Teaching Hospital (CSTH) is the second largest government hospital in Colombo (USJ, 2012). The hospital consists of 2320 staff of which 347 are doctors and 716 are nurses (USJ, 2012). The bed capacity of the hospital is 1093 and involves around 150,000 patient admissions and 75, 000 out patients per year (USJ, 2012). Many medical professionals at CSTH tend to take immense career satisfaction in delivering health care to their patients. However due to the work load, work environment, work hours and other occupational stressors, they often feel exhausted at work. Furthermore some medical professionals even indicated that the exhaustive nature of their work had an impact on their personal lives where the anger, stress, frustration were vented down to their family and other individuals.

The knowledge accumulated over the years on occupational stress among health care provides a poor representation of chronic stress experienced by them and its impact on their work performance (Diez - Pinol et al., 2007). Other researchers indicate that by concentrating on identifying individuals with chronic stress, causes of these stress (stressors) and possible coping strategies to stressful situations would enable an organization to generate a well-motivated workforce(de Valk\& Werner, 2000). A healthy motivated workforce would undoubtedly create sustainable competitive advantage for the organization (de Valk \&Werner, 2000).

Burnout syndrome results from chronic stress related to the job characteristics mainly experienced by individuals who engage in 'people - work' (Maslach \& Jackson, 1981: Maslach, Jackson \& Leiter, 1996). Therefore professionals in a medical setting are considered to be more prone to burnout due to their job nature (Samuel \& Rosalie, 2011). Certain epidemiological studies in the health sector have revealed that burnout is increasing at an alarming rate among physicians, particularly for those who work in the public sector (Dolan, Gracia \& Auerbach, 2003).

The most recurrent causes for burnout syndrome are excessive bureaucratic nature of work, excess paper work, heavy work load, work family conflict and other work conditions (Maslach, Shaufeli \& Leiter, 2001). Similarly other scholars indicate that demographic factors contribute to work family conflict where women appear to be more burned out than men (Firth - Cozens, 2007). By identifying the causes of the syndrome it is possible to mitigate its negative effects.

In terms of coping strategies to stressful situations it is important to identify the current coping practices of medical professionals. According to Lazarus and Folkman (1984) there are two major coping strategies that many individuals engage themselves in a stressful situation. These are named emotion focused coping and problem focused coping strategies (Lazarus \& Folkman, 1984; Bond \& Bunce, 2000). Problem focused coping strategy attempts to resolve and manage 
the problem from the root cause, whereas emotion focused strategy would involve reducing, regulating or removing the source of stress (Lazarus \& Folkman, 1984; Bond \& Bunce, 2000). Therefore emotion focused coping strategies give rise to harmful habits such as alcohol, substance abuse and illegal drugs (Lazarus \& Folkman, 1984; Bond \& Bunce, 2000).

The main objective of the paper is to describe the proportion of burnout syndrome among medical professionals practicing in Colombo South Teaching Hospital (CSTH), describe the causes and analyse coping strategies for stressful situations practiced by medical professionals. This study aimed at filling the gap in the literature in relation to burnout syndrome in medical professionals in Sri Lanka, with a focus on identifying the associated causes and coping strategies to mitigate its negative effects.

\section{Literature Review}

Burnout syndrome has been defined as a prolonged response to chronic interpersonal and emotional stressors on the job, determined by cynicism, inefficacy and exhaustion (Montero Marin \& Garcia - Campayo, 2010). In more general terms Faber (2000) describes the syndrome as an individual's response to the failure of the coping strategies a person typically utilize to manage stress at work. Definition of 'burnout syndrome' accepted widely across the world is based on the work initiated and proposed by Maslach (1976). Maslach, Jackson and Leiter (1996) defined Burnout Syndrome as a syndrome of emotional exhaustion, depersonalization and reduced personal accomplishment that is experienced by individuals who perform people work in some capacity (Maslach, Jackson \& Leiter, 1996). The syndrome consists of three main dimensions namely depersonalization, lack of personal accomplishment and emotional exhaustion (Maslach, 1982). The three constructs of burnout syndrome are described as follows.

Firstly emotional exhaustion (EE) dimension is said to be the central manifestation of burnout syndrome (Maslach, Shaufeli \& Leiter, 2001). This dimension refers to a way individual feels on the job where he feels excessive emotional stress and as a result drained by work that involved contact with other people (Maslach, Shaufeli \& Leiter, 2001). Emotional exhaustion is considered to be the most important dimension of burnout syndrome where some scholars have even argued that if EE dimension is scored positive then there is no necessity to identify the prevalence of other two dimensions (Shirom, 1989).

Second dimension is called depersonalization (DP) which refers to an attempt by an individual to actively ignore and create a distance between one's self and the recipient of the service (Maslach, Shaufeli\&Leiter, 2001). In such a case the individual would develop an unresponsive and callous response towards patients (Ellahi \& Mashtaq, 2012). Medical professionals experiencing depersonalization would respond to their patients in a harsh and impersonal manner (Ellahi \& Mashtaq, 2012). The third dimension is personal accomplishment (PA), which involves developing a feeling of reduced sense of competency and efficacy with the tasks they perform on the job (Ellahi \& Mashtaq, 2012). Medical professionals who are experiencing reduced personal accomplishment are likely to observe pessimism, poor judgment and feelings of incompetence during their work (Ellahi \& Mashtaq, 2012). A reaction such as reduced personal accomplishment in the health care setting is said to lead to a strong relationship starting from exhaustion and leading to cynicism (Maslach, Shaufeli \& Leiter, 2001). In certain cases it is 
stated that reduced personal accomplishment is a product of exhaustion, cynicism or a combination of the two (Byrne, 1994).

Burnout syndrome is said to incur many severe consequences at two levels namely individual and organizational. According to Chlan and Linda (2013), burnout syndrome results in serious mental health consequences to physicians who are emotionally exhausted. These mental health consequences include anxiety, depression, alcohol and substance misuse, and suicide (Chlan \& Linda, 2013). Confirming this further De Valk and Oostrom (2007) state that serious problems brought on by failure to cope with demanding situation include marital problems, emotional disorders and substance misuse. In an organizational context burnout syndrome would result in high turnover, low morale, low job satisfaction and reduced quality of service provided (Maslach, Jackson, \& Leiter, 1996; Samuel \& Rosalie, 2011). Experienced at an organizational level, side effects include absenteeism, reduced ability to work, frequent delays, various complaints, low morale, reduced quality of service provided, conflict in the work environment and turnover (Wu et al., 2008). De Valk and Oostrom (2007) observed that job satisfaction among medical professionals who experienced burnout syndrome was drastically low compared to those who did not suffer from the syndrome. The study observed physicians to find their work unrewarding, constantly in conflict at work and believed they were being treated unfairly.

Burnout syndrome among medical professionals is of vital importance to hospitals because the negative consequences of the syndrome would impact on the patient care provided. According to Montgomery et al., (2010) Burnout Syndrome reduces the ability of medical professionals to provide the best quality of care for their patients. Burned out medical professionals are likely to cause medical errors, such errors could even be fatal for the patients (Montgomery et al., 2010) and among physicians could have implications for the quality of care provided for the patient, result in medical error \&/or even patient death (Shanafelt et al., 2005). Reduced quality of care to patients, high likelihood of mistakes and highly stressed medical professionals working in a hospital would contribute towards the detriment of the brand image of the entity (Kinzl et al., 2006).

Figure1: Burnout syndrome and its consequences on individuals, patients and for the hospital

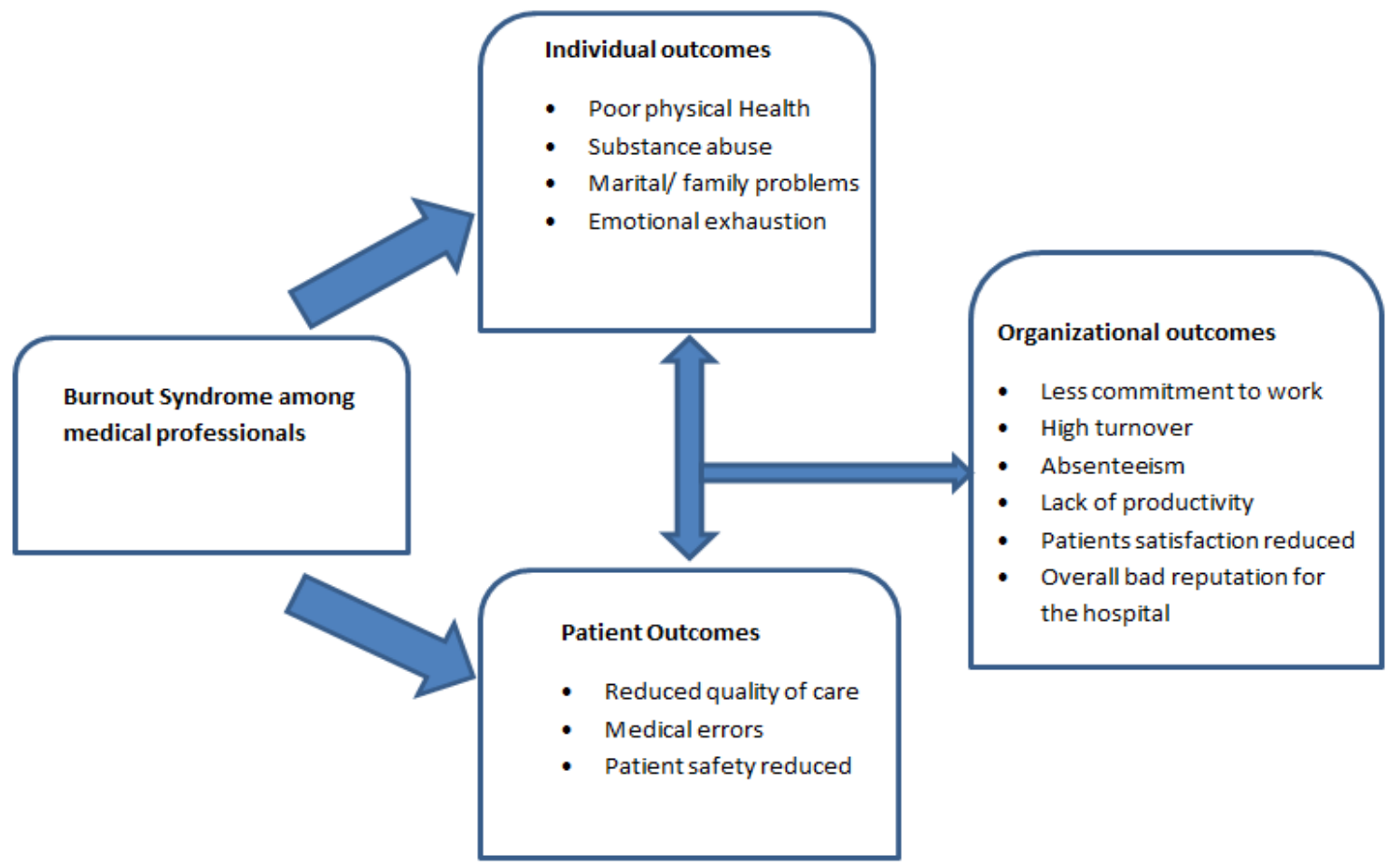


Assessment of burnout syndrome among doctors in Sri Lanka, has not been addressed directly by any scholar or researcher up to now. A senior medical professional stated that there has been an increased rate of work - family conflict especially among female doctors in Sri Lanka (Gunawardhana, 2014). Also there have been an increased number of medical professionals experiencing job dissatisfaction, high occupational stress and job burnout, thus elaborating the importance of the area of study (Gunawardhana, 2014).

\section{Conceptual framework and hypotheses}

According to Maslach, Shaufeli \& Leiter (2001) burnout syndrome occurs due to the exposure of an individual to stressors over a long period of time on the job. Most frequently elaborated correlates of the syndrome appear to be excess paper work, excessive bureaucratic nature of the work, heavy work load, lack of autonomy to make decisions, policy issues, conflict in roles, and monotonous routine nature of work with low work variety (Linzer et al., 2001). Similarly other scholars too identify that factors such as workload, team dynamics, demographic factors, (Carter \& West, 1999); work family conflict, monotonous nature of work, job instability and lack of support (Firth-Cozens, 1998) as the most common causes of the burnout syndrome. It is also established that burnout syndrome is most widely reported in human service professionals due to their job being involved with having heavy human contact (Maslach, Shaufeli \& Leiter, 2001).

\section{The number of work hours and workload}

Maslach, Shaufeli \& Leiter (2001) suggest quantitative job demands such as too much work to complete in a short period of time are associated with burnout syndrome. This is where workers feel they have a heavy workload and time pressure which in turn correlate to emotional exhaustion dimension (Maslach, Shaufeli \& Leiter, 2001). In medical setting, one of the primary causes of burnout syndrome appear to be heavy workload that is typically measured by number of work hours (Chlan and Linda 2013). It was established that 57\% of study population experienced the syndrome due to higher number of work hours (Aguir, Baena \& Perez - Hoyos 2005). In the case of medical professionals in Sri Lanka, there is trend of doctors working at the government hospital during the day time according to shift basis and working part time at private hospitals for generating extra income. This extra work load and the time spend would result in burnout syndrome.

Contradictory results are found in other publications elaborating that there is no significant relationship between number of work hours and burnout syndrome (Weinberg \& Creed, 2000, Barbosa et al., 2012).

Hypothesis 1: Higher number of working hours and heavy work load is positively correlated to burnout syndrome among medical professionals practicing at CSTH.

\section{Work family conflict}

As the number of dual - career families has steeply increased over the past years, work family conflict has become a major source of stress for individuals (Braunstein-Bercovitz, 2013). Such has become the case because many adults are increasingly faced with the difficult task of both meeting work - related demands and family obligations (Halpern, 2005). Work family conflict is defined as a form of inter - role conflict in which role pressures from the family and work 
domains become mutually incompatible, thus cause strain in an individual (Greenhaus \& Beutell, 1985).

Main causes of work family conflict are said to be due to time pressure which results in stress and fatigue being spilled over to the family (Braunstein-Bercovitz, 2013). With an increase in the number of hours worked and the corresponding work load, many medical professionals are faced with a dilemma of providing the necessary care to patients (Karatepe \&Tekinkus, 2006). As a result the emotional exhaustion dimension of burnout syndrome and work family conflict seem to have a strong link as evident in the literature (Karatepe \& Tekinkus, 2006). This fact is confirmed by Maslach, Shaufeli \& Leiter (2001).

Burnout syndrome seems to affect women more than men. Elaborating this concept further it is reported that among 978 medical professionals, more females were prone to burnout syndrome than the males (Embriaco et al., 2007). According to Burke, Koyuncu and Firsenbaum (2008) in a study population of 194 females and 237 males, a higher number of female physicians have reported that they experience burnout syndrome as a result of high occurrence of work family conflict. Such a case is evident because females have more assumed responsibility over taking care of their family/ children, because of the way in which society depicts gender roles (Embriaco et al., 2007).

Contradictory findings indicate that there is no such established relationship between gender and the syndrome (Erdur et al., 2006). Higher levels of burned-out individuals were seen to be less frequently married or partnered and more often did not have children (Embriaco et al., 2007). Since there is much confusion on burnout syndrome and its prevalence among the two genders it is important to test the following hypotheses.

Hypothesis 2: Work - family conflict is positively correlated to burnout syndrome among medical professionals practicing at $\mathrm{CSTH}$

Hypothesis 3: Work - family conflict is positively correlated to the emotional exhaustion dimension of burnout syndrome

Hypothesis 4: Female medical professionals are more likely to experience burnout syndrome than males.

\section{Unpleasant work environment and lack of resources to provide necessary patient care}

Another cause of occupational stress in health care service sector appears to be the absence of adequate resources to provide sufficient care for patients (Maslach, Shaufeli \& Leiter, 2001). The resource that has been studied most extensively is social support and organizational resources (Maslach, Shaufeli \& Leiter, 2001). Lack of support from coworkers, supervisors together with limited resources to perform patient work can cause continuous strain in medical professionals.

Many medical professionals employed at government hospitals in developing countries such as Sri Lanka have very limited access to adequate resources as a result they are under constant pressure. Demanding workload with low control and autonomy at work would result in burnout syndrome (De Valk \& Oostrom, 2007). Therefore medical professionals are strained due to having limited resources to perform adequate care; such may become a stressor in the work place and would correlate to burnout syndrome positively. Confirming this further Embriaco et al. 
(2006) suggest that lack of resources to perform adequate care in intensive care units has caused stress among doctors. However certain studies have not successfully established a correlation between lack of organizational resources and burnout syndrome (Maslach, Shaufeli \& Leiter, 2001).

Hypothesis 5: Inadequate resources and unfriendly relationships which result in unpleasant work have a positive influence on burnout syndrome among medical professionals.

\section{Low autonomy/ control at work}

Maslach, Shaufeli \& Leiter (2001) suggested that burnout syndrome occurs more frequently when there is an incongruity between the individual and the organization related to main areas of work such as fairness, rewards, community, control and work load. As such control and autonomy at work provide an interesting avenue that could be a root cause of burnout syndrome. Spickard, Gabbe and Christensen (2009) state that perceived lack of control over work and exceeding workload related to capacity result in the syndrome. According to Bruce (2004) certain studies have failed to establish a relationship between control at work and Burnout Syndrome. In the case of medical professionals working in Sri Lanka the problem of having low autonomy was mentioned by a few individuals to the hospital director of CSTH.

Hypothesis 6: Lack of autonomy/control at work is positively related to burnout syndrome.

\section{High personal contact nature of the job}

Almost all of burnout research in the occupational health sector of human services has developed a particular concern for individuals working intensively with other people (Maslach, Shaufeli \& Leiter, 2001). Therefore as suggested by Maslach, Shaufeli \& Leiter (2001) it was more evident that emotional stressors of people - work were a unique cause particularly related to burnout syndrome, among individuals who perform people work. However certain studies have not found much evidence to support a correlation between high personal contact nature of the job and burnout syndrome, but instead have focused more on work load, role conflicts and time pressure (Maslach, Shaufeli \& Leiter, 2001).

Hypothesis 7: High personal contact nature of the job, difficult interactions with patients and risk of patient death correlate positively with burnout syndrome.

\section{Risk of having major failures of duty and patient death}

It is a common occurrence that medical professionals tend to be attached to their patients emotionally when providing care (Quill \& Williamson, 1990). When such happens Physicians are said to reflect a need to rescue patients from serious illness and sometimes would feel powerless in the event they cannot help the patient to recover (Meier, Back \& Morrison, 2007). As a result the physicians would become extremely stressed, burned - out and even disengage from work (Meier, Back \& Morrison, 2007). Furthermore the life and death struggles of patients and emotionally demanding contact can be exhausting for medical professionals practicing in the emergency care units of hospitals (Linda \&Chlan, 2013).

New research has indicated that high contact with chronically and terminally ill patients and confrontations with death and dying, is a major cause of occupational stress, thus burnout syndrome (Zapf et al., 2001). Also a correlation between the number of death in a ward and a 
perception of being emotionally exhausted and overwhelmed was established in a study among French intensive care specialists (Baldwin et al., 1997).

Hypothesis 8: Risk of major failures on duty and/or patient death has a positive association with burnout syndrome.

\section{Coping strategies}

Coping is defined as a pattern of constructed behavior towards situations deemed stressful, with the aim of mitigating/ avoiding its negative effects (Lazarus \&Folkman, 1984; Bond \&Bunce, 2000).It was noted that problem - focused coping strategy attempts to resolve \&/or manage the root cause of the problem, whereas emotion focused strategy consists of efforts towards regulating, reducing, or removing the psychological distress caused by the stressor (Lazarus \& Folkman, 1984; Bond \& Bunce, 2000).

When problem focused coping strategy is undertaken by healthcare professionals; they tend to find methods of stopping or removing the source of stress (Lee, Stewart \& Brown, 2008). As suggested by Evans and Kelly (2004), this coping strategy is driven from the locus of control where one believes, he or she has certain control over a work situation. Among medical professionals this form of coping strategy is considered to take a positive stance relating to burnout issues, thus logically this strategy is considered to be a better option for the individual to cope with stress (Ellawala, 2010).

Emotion - focused coping strategy on the other hand is based on exact opposite, where the individuals feel they do not have adequate control over the situation and the causes of stress (Lee, Stewart \& Brown, 2008). Hence most medical professionals would tolerate the stress source, try to avoid the problem at hand, and resort to other coping mechanisms such as alcohol, substance abuse, religion that do not directly try to resolve the root cause of the problem. Montgomery et al. (2010) state that there is a significant number of doctors who are using illegal drugs and alcohol as a coping strategy. Predictably it is stated that problem focused coping strategies are better than emotion focused coping strategies in most literature (Ellawala, 2010).

\section{Methodology}

Total number of medical professionals practicing at CSTH is 395, out of which 100 were selected randomly. Simple random sampling technique was taken by obtaining a list of medical professionals practicing at CSTH from the director of the hospital and selected every third doctor in the list ensuring a representative sample. The data collection was conducted within a particular time period with no extensions being made, therefore the study could be classified as a cross sectional study.

A questionnaire was developed on four dimensions. Firstly a self-administered demographic information section, secondly a self-administered questionnaire to analyze the causes of burnout syndrome, thirdly the questionnaire hosted the Maslach Burnout Inventory - HSS to assess the existence of the syndrome among medical professionals and finally coping strategies questionnaire developed and tested by Ellawala (2010) were used. The relationship between the cause and effect was tested by using the pre - generated hypothesis. Therefore this part of the study was correlational rather than causal in nature. As the study attempted to establish a 
relationship between causes of stressors and burnout syndrome this study was analytical in nature.

A consultant doctor and the primary investigator hand delivered the questionnaire to each medical professional. Hand delivering the questionnaire helped the respondent to clarify their doubts. Filling of the questionnaire took around 10 - 15 minutes. Most of the medical professionals filled out the survey then and there and handed over to the primary investigator. Response rate was 80\%. 20 questionnaires were considered as incomplete. Further 20 questionnaires were handed out to randomly selected doctors one week later and 100 were achieved.

\section{Measures}

Demographic profile and stressors at work place (instrument 1) - This study specific selfadministered questionnaire was constructed by the researchers to measure the demographic characteristics of the study population, associated work situational characteristics and correlates of burnout syndrome. This was developed after carrying out the literature search and analyzing the characteristics of the study population.

First part of the questionnaire consists of 13 questions relating to the demographic profile of the respondents and the second part involves 8 situations at work where the respondents should record how often they felt stressed in a particular situation. This questionnaire was developed after conducting a literature review and identifying the most recurring stressors for medical professionals in the published research. The questionnaire attempts to reveal how each stressor influenced on an individual. The results for each item were scored on a scale of never, sometimes and frequently. The results were then tested against the individuals who scored positive on burnout syndrome to test the pre- developed hypotheses.

MBI - HSS (instrument 2)- Maslach \& Jackson (1981) developed the world renowned tool named 'Maslach Burnout Inventory' to test burnout syndrome. MBI consists of 22 items that assesse the scores of three components namely, emotional exhaustion (EE), depersonalization (DP), and reduced personal accomplishment (PA). Each item was rated with a score from (0) never to (6)- everyday. The results of these constructs were used to form three separate scores measured among each dimension of EE, DP and PA. Many researchers have established that MBI - HSS is the most valid tool to assess burnout syndrome in health care workers (Lee, Stewart \& Brown, 2008).

- Emotional exhaustion(EE) measures feelings of being emotionally overextended and exhausted by one's work

- Depersonalization(DP) measures an unfeeling and impersonal response toward recipients of one's service, care treatment, or instruction

- Personal accomplishment(PA) measures feelings of competence and successful achievement in one's work

Maslach Burnout Inventory - HSS was validated in Sri Lanka by Samaranayake and Seneviratne (2010) to assess the burnout syndrome among a random sample of 191 nursing officers in the North Colombo Teaching Hospital. The cut off values developed by Samaranayake and Seneviratne (2010) to test the burnout level among nurses in Sri Lanka were used to test the burnout level among medical professionals with the permission from the authors. Given the high 
validity across many countries and in particular Sri Lanka this instrument was used to assess the status of burnout among the study population. See Table 1.

Table 1: Summary of validity indicators of the MBI-HSS at identified cut off points (Samaranayake \& Seneviratne, 2010)

\begin{tabular}{|l|l|l|l|l|l|l|}
\hline Number of items & MBI score & Cut off value & Sensitivity & specificity & PPV & NPV \\
\hline 22 & Total score & 32 & $93.3 \%$ & $87.7 \%$ & $88.3 \%$ & $92.9 \%$ \\
\hline 9 & EE score & 18 & $95.6 \%$ & $89.7 \%$ & $90.3 \%$ & $95.3 \%$ \\
\hline 5 & DP score & 5.5 & $91.1 \%$ & $82.9 \%$ & $84.2 \%$ & $90.3 \%$ \\
\hline 8 & PA score & 8.5 & $84.4 \%$ & $80.1 \%$ & $80.9 \%$ & $83.7 \%$ \\
\hline
\end{tabular}

Coping strategies (instrument 3) - This is a self-administered questionnaire adapted and validated by Ellawala among nurses in Sri Lanka (Ellawala, 2010). With the approval of the author the questionnaire was used to analyze the coping strategies practiced by medical professionals.

This questionnaire consists of 14 items that attempt to identify the coping strategies currently practiced by medical professionals for certain stressful situations at work. The answers were recorded as never, sometimes and frequently for each item in the questionnaire. The answers were then formulated into a percentage to determine the type of coping strategies practiced by medical professionals with an emphasis on further identifying any harmful coping strategies currently in place.

\section{Statistical Analysis}

SPSS version 12 was used to analyze the data. Data of the demographic profile were presented in mean and ranges. The pre - developed hypotheses were tested using Chi - Square test in order to derive the statistical significance of difference. Cut off value was taken as $\mathrm{P}<0.05$. Causative factors that had $\mathrm{P}$ values $<0.05$ were considered to have sufficient statistical evidence to conclude that there is a significant relationship between the stressor and burnout syndrome at $5 \%$ significance level. For any $\mathrm{P}$ values $>0.05$ there was sufficient statistical evidence to conclude that there is no significant relationship between the stressor and burnout syndrome. The degree of freedom was taken as 1 throughout the process of analysis.

\section{Results}

The demographic profile of the sample consisted of 46 males and 54 females. The proportions of medical professionals were 50 in the $25-34$ group, 24 in the $35-44$ group, 18 in the $45-54$ group and 8 in the over 55 year group.There were 75 medical professionals who were married and 25 were single. In terms of average working hours 38 medical professionals worked less than 6 hours, 44 worked for $7-11$ hours and 18 worked for more than 12 hours per day. 
Table 2: Associated causes with the corresponding scores for each dimension E.E, D.P, P.A and the combined score for burnout syndrome

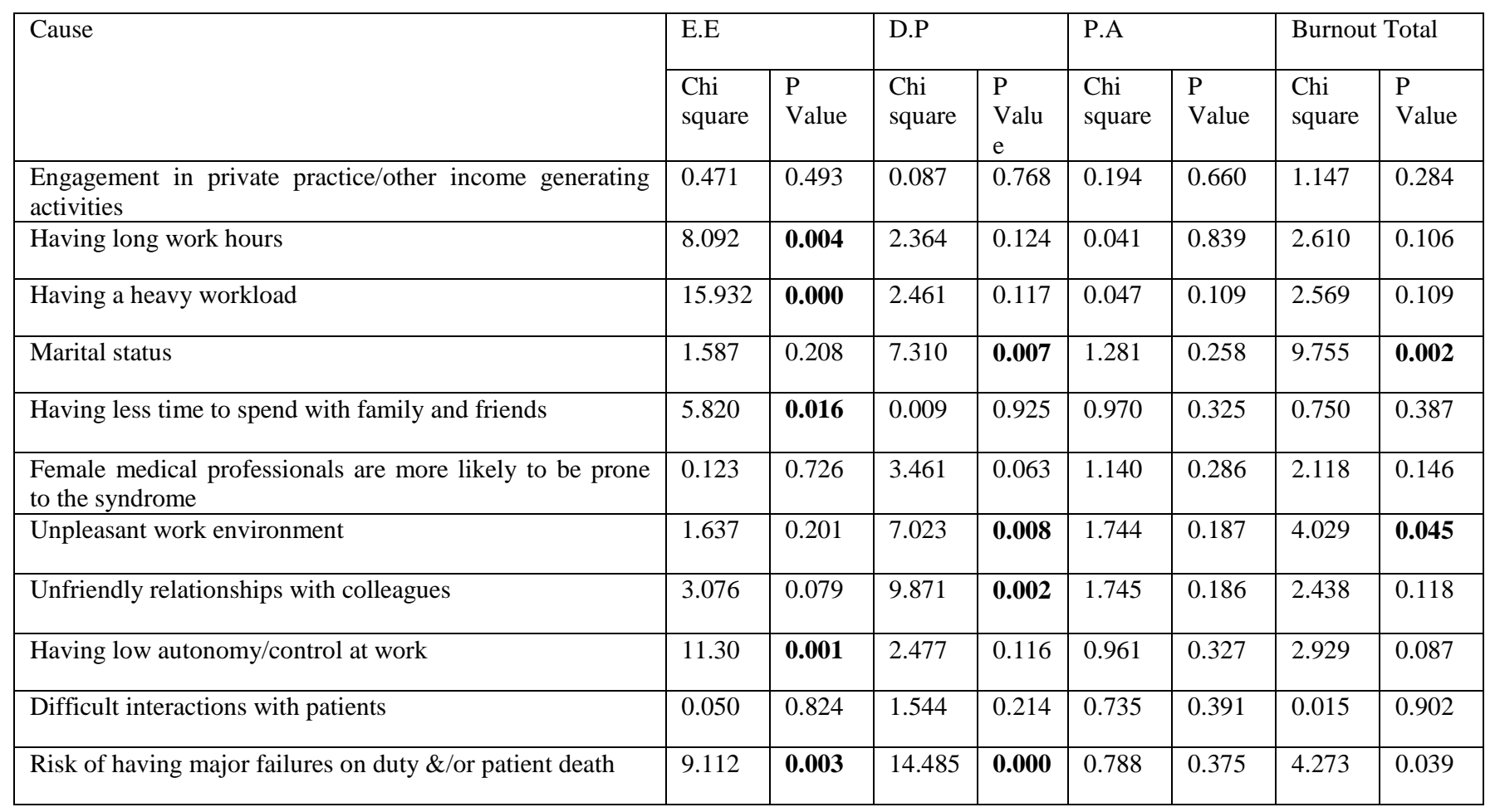

When considering the causative factors of burnout syndrome it was evident that the following factors had a significant relationship with the syndrome. Refer to Table 2. Firstly number of work hours and burnout syndrome E.E dimension had positive correlation with the syndrome (Pvalue 0.004 ). Secondly the work load had a positive correlation with the burnout syndrome E.E dimension ( $\mathrm{P}$ - value 0.00). Also there was a positive correlation between marital status and burnout syndrome D.P dimension ( $\mathrm{P}-$ Value 0.007). Considering all three dimensions EE, DP and PA a P value of 0.002 was obtained suggesting that burnout syndrome overall score is positively correlated to marital status of medical professionals. Furthermore a significant relationship was evident where having less time to spend with family/ friends and E.E dimension of burnout syndrome ( $\mathrm{P}$ value - 0.016). Another significant relationship between unpleasant work environment and burnout syndrome D.P dimension ( $\mathrm{P}$ value -0.008 ) as well as in the overall score of all three dimensions (EE/DP/PA) of the syndrome was observed ( $\mathrm{P}$ value -0.045$)$. In terms of work environment it was also established that unfriendly relationships with colleagues correlated positively with the D.P dimension of the syndrome (P - value 0.002$)$ and having low autonomy/ control correlated positively with the E.E dimension of the syndrome $(\mathrm{P}-\mathrm{Value}$ 0.001). Fear of major duty failure and/or patient death had a positive correlation with E.E dimension ( $\mathrm{P}-$ Value 0.003), DP dimension ( $\mathrm{P}-$ Value 0.000) and in the overall score for burnout syndrome (EE, DP, PA) in all three dimensions (P Value - 0.039). 
Table 3: Proportion of burnout syndrome

\begin{tabular}{|l|l|l|}
\hline BOS dimension & Frequency & Percentage \\
\hline EE BOS - & 70 & 70 \\
\hline EE BOS + & 30 & 30 \\
\hline Total & $\mathbf{1 0 0}$ & $\mathbf{1 0 0}$ \\
\hline DP BOS - & 76 & 76 \\
\hline DP BOS + & 24 & 24 \\
\hline Total & $\mathbf{1 0 0}$ & $\mathbf{1 0 0}$ \\
\hline PA BOS - & 15 & 15 \\
\hline PA BOS + & 85 & 85 \\
\hline Total & $\mathbf{1 0 0}$ & $\mathbf{1 0 0}$ \\
\hline BOS total - & 47 & 47 \\
\hline BOS total + & 53 & 53 \\
\hline Total & $\mathbf{1 0 0}$ & $\mathbf{1 0 0}$ \\
\hline
\end{tabular}

Refer to Table 3. Burnout syndrome in EE dimension $30 \%$ of the population has scored positive in the sample (30 Individuals). Consequently $24 \%$ has scored positive in the DP dimension and $85 \%$ scored positive in the PA dimension. Considering the overall score for the syndrome (EE/DP/PA) 53\% has scored positive and is evidently suffering from the Burnout Syndrome.

Table 4: Coping strategies employed by the medical professionals of the study sample

\begin{tabular}{|c|c|c|c|c|c|c|c|c|}
\hline \multirow{3}{*}{$\begin{array}{l}\text { Situation/ coping strategy } \\
\text { (Problem focused ) }\end{array}$} & \multicolumn{6}{|c|}{ Frequency } & \multirow{2}{*}{\multicolumn{2}{|c|}{ Total }} \\
\hline & \multicolumn{2}{|c|}{ Never } & \multicolumn{2}{|c|}{ Sometimes } & \multicolumn{2}{|c|}{ Frequently } & & \\
\hline & No. & $\%$ & No. & $\%$ & No. & $\%$ & No. & $\%$ \\
\hline $\begin{array}{l}\text { I have looked for something good that happened } \\
\text { in a situation and tried to make it seem more } \\
\text { positive }\end{array}$ & 1 & 1 & 64 & 64 & 35 & 35 & 100 & 100 \\
\hline $\begin{array}{l}\text { I thought hard about what steps to take and tried } \\
\text { to come up with an appropriate strategy }\end{array}$ & 0 & 0 & 58 & 58 & 42 & 42 & 100 & 100 \\
\hline $\begin{array}{l}\text { I tried to get advice from relevant people and } \\
\text { worked accordingly }\end{array}$ & 2 & 2 & 43 & 43 & 55 & 55 & 100 & 100 \\
\hline $\begin{array}{l}\text { I put aside other activities in order to concentrate } \\
\text { on this }\end{array}$ & 10 & 10 & 67 & 67 & 23 & 23 & 100 & 100 \\
\hline $\begin{array}{l}\text { I forced my-self to not make matters worse by } \\
\text { acting too soon and waiting for the right time to } \\
\text { do so }\end{array}$ & 5 & 5 & 65 & 65 & 30 & 30 & 100 & 100 \\
\hline
\end{tabular}

Refer to Table 4 . Of the study sample $64 \%$ sometimes looked for something good that happened in a situation and tried to stay positive where as $35 \%$ frequently resorted to the same strategy. Another 58\% sometimes tried to come up with an appropriate strategy, where as $42 \%$ frequently 
did the same. Among medical officers, frequently practicing problem - focused coping strategy was 'tried to get advice from relevant people and worked accordingly' scored the highest (55\%, and $43 \%$ sometimes resorted to this strategy). Also another $67 \%$ sometimes put aside other activities in order to concentrate on the problem and another $23 \%$ frequently did the same. $65 \%$ sometimes forced themselves to not act too soon and $30 \%$ engaged in the same frequently. Evidently more than $40 \%$ of medical officers practiced each of problem focused coping strategies sometimes.

Table 5: Emotional harmless strategies

\begin{tabular}{|l|l|l|l|l|l|l|l|l|l|}
\hline \multirow{2}{*}{$\begin{array}{l}\text { Situation/ coping strategy } \\
\text { (Emotional harmless ) }\end{array}$} & \multicolumn{4}{|l|}{ Frequency } & \multicolumn{2}{l|}{ Total } \\
\cline { 2 - 10 } & Never & Sometimes & Frequently & \multicolumn{2}{l|}{} \\
\cline { 2 - 11 } & No. & $\%$ & No. & $\%$ & No & $\%$ & No. & $\%$ \\
\hline I tried to reduce stress by physical exercise & 31 & 3 & 56 & 56 & 13 & 13 & 100 & 100 \\
\hline $\begin{array}{l}\text { I tried to find comfort in my religion and spiritual } \\
\text { beliefs }\end{array}$ & 19 & 1 & 60 & 60 & 21 & 21 & 100 & 100 \\
\hline I try to reduce stress by listening to music & 9 & 9 & 62 & 62 & 29 & 29 & 100 & 100 \\
\hline $\begin{array}{l}\text { I tried to get emotional support and comfort from } \\
\text { friends/ colleagues }\end{array}$ & 10 & 1 & 66 & 66 & 24 & 24 & 100 & 100 \\
\hline
\end{tabular}

Refer to Table 5. Of the sample studied $56 \%$ sometimes tried to alleviate stress by exercising, $31 \%$ never and $13 \%$ frequently engaged in this strategy. Of the sample $60 \%$ sometimes tried to reduce stress by engaging in religious and spiritual beliefs and another $29 \%$ frequently engaged in the same. Evidently $29 \%$ of the medical officers were frequently practiced listening to music to reduce stress and a high of $62 \%$ sometimes engaged in this strategy. Majority of the medical officers were sometimes practicing getting emotional support and comfort from friends/ colleagues and $24 \%$ frequently tried to get support.

Table 6: Emotional harmful coping strategies

\begin{tabular}{|c|c|c|c|c|c|c|c|c|}
\hline \multirow{3}{*}{$\begin{array}{l}\text { Situation/ coping strategy } \\
\text { (Emotional harmful) }\end{array}$} & \multicolumn{6}{|c|}{ Frequency } & \multirow{2}{*}{\multicolumn{2}{|c|}{ Total }} \\
\hline & \multicolumn{2}{|c|}{ Never } & \multicolumn{2}{|c|}{ Sometimes } & \multicolumn{2}{|c|}{ Frequently } & & \\
\hline & No. & $\%$ & No. & $\%$ & $\begin{array}{l}\mathrm{N} \\
\mathrm{O} .\end{array}$ & $\%$ & No. & $\%$ \\
\hline $\begin{array}{l}\text { I took alcohol or other substance to find } \\
\text { comfort in the situation }\end{array}$ & 92 & 92 & 7 & 7 & 1 & 1 & 100 & 100 \\
\hline $\begin{array}{l}\text { I kept all feelings to myself and tried to deal } \\
\text { without expressing and blamed myself for } \\
\text { what has happened }\end{array}$ & 34 & 34 & 57 & 57 & 9 & 9 & 100 & 100 \\
\hline I starved or over ate & 50 & 50 & 41 & 41 & 9 & 9 & 100 & 100 \\
\hline
\end{tabular}

Refer to Table 6. Majority of medical officers never practiced the harmful stress coping strategy of taking alcohol or other substance to find comfort the situation (92\%). However $57 \%$ of the sample sometimes kept all feelings to themselves and tried to deal with it by blaming themselves, another $9 \%$ frequently resorted to this strategy. $50 \%$ of medical officers never practiced starving or over eating, where as $47 \%$ sometimes engaged in starving or binge eating. 
Table 7: Cognitive copying strategies

\begin{tabular}{|l|l|l|l|l|l|l|l|l|l|}
\hline \multirow{2}{*}{$\begin{array}{l}\text { Situation/ coping strategy } \\
\text { (Cognitive) }\end{array}$} & \multicolumn{3}{l|}{ Frequency } & \multicolumn{2}{l|}{ Total } \\
\cline { 2 - 9 } & Never & So. & $\%$ & No. & $\%$ & No. & $\%$ & No. & $\%$ \\
\cline { 2 - 9 } & & 2 & 2 & 84 & 84 & 14 & 14 & 100 & 100 \\
\hline I reappraised the situation to make it less stressful & 2 & 11 & 78 & 78 & 11 & 11 & 100 & 100 \\
\hline I tried to think that it is not worth serious concern & 11 & & & & & & & & \\
\hline
\end{tabular}

Refer to Table 7 . The proportion of medical officers who were frequently reappraised the situation to make it less stressful was $14 \%$ and $84 \%$ conformed to this strategy sometimes. $11 \%$ of the medical officers were frequently trying to think that the situation is not worth serious concern where as $78 \%$ classified this as sometimes.

\section{Discussion}

\section{Does burnout syndrome exist at CSTH?}

The findings of the study illustrate that E.E dimension exists among $30 \%$ of medical professionals, D.P dimensions among $24 \%$ and P.A dimension in $85 \%$. Considering all three dimensions it was evident that 53 individuals were suffering from burnout syndrome and 47 individuals were classified as normal. The findings indicate that CSTH management should take immediate action to increase the work life balance of the medical professionals.

In similar studies it was found that burnout syndrome among physicians was as high as $72 \%$ (Roth et al., 2011). Another study reported that around $42 \%$ of respondents in the healthcare setting were burned out (Lu et al., 2005). Around half of 878 intensive care specialists in France were reported as having high level of burnout (Carod - Artal \& Vazquez - Cabrera, 2013).Similarly among 151 resident physicians in Seattle around $76 \%$ had met the criteria for the burnout syndrome (Shanafelt et al., 2002). Sharma et al., (2008) found out that more than 500 surgeons have exhibited symptoms of burnout syndrome in India. In Germany it was revealed that $25 \%$ of 89 medical professionals scored high on E.E and D.P dimension and $1 / 5^{\text {th }}$ revealed scores of P.A (Kinzl et al., 2006). From the findings it is possible to state that the syndrome has a high prevalence more than $50 \%$ at CSTH in Sri Lanka. Such significant findings in burnout syndrome in the health services sector in Sri Lanka indicate that it is imperative to develop strategies to prevent the occurrence of the syndrome.

\section{Discussion of findings of the validity of the pre - established hypotheses}

According to Lee and Ashworth (1993) burnout syndrome initiates from depersonalization, then proceeds through to emotional exhaustion and progresses to reduced personal accomplishment. It is stated that emotional exhaustion component of the burnout syndrome is considered to be the most important dimension of all (Hakanen\&Schaufeli, 2012). As suggested by Hakanen and Schaufeli (2012) E.E dimension of the syndrome has close associations to other types of mental illness such as anxiety and depression. Furthermore according to Maslach, Shaufeli \& Leiter (2001), E.E dimension and D.P dimension are the most important aspects of the syndrome. These two dimensions are considered to form the core components of burnout syndrome (Greene, 1991). Therefore the implication from this study focuses on the importance of identifying E.E and D.P dimensions as well as the overall score for Burnout syndrome. 
Table 8: Correlation of burnout syndrome and hypothesized causative factors (derived from the $p$ value of the chi square test)

\begin{tabular}{|c|c|c|c|c|c|c|}
\hline Hypothesis & Measures & E.E & D.P & P.A & Total & \\
\hline \multirow[t]{2}{*}{$\begin{array}{l}\text { Hypothesis 1: } \\
\text { Higher number } \\
\text { of working hours } \\
\text { and heavy work } \\
\text { load is positively } \\
\text { correlated to } \\
\text { burnout } \\
\text { syndrome among } \\
\text { medical } \\
\text { professionals } \\
\text { practicing at } \\
\text { CSTH }\end{array}$} & $\begin{array}{l}\text { Whether the medical } \\
\text { professionals engaged in private } \\
\text { practice/ other income generating } \\
\text { activities (Question 8) }\end{array}$ & + & - & - & - & $\begin{array}{l}\text { Since E.E } \\
\text { dimension is } \\
\text { positive the } \\
\text { finding is } \\
\text { significant. }\end{array}$ \\
\hline & $\begin{array}{l}\text { How often the medical } \\
\text { professionals felt that they had a } \\
\text { heavy work load (Question13.2) }\end{array}$ & + & - & - & - & $\begin{array}{l}\text { Since E.E } \\
\text { dimension is } \\
\text { positive this } \\
\text { finding is } \\
\text { significant. }\end{array}$ \\
\hline $\begin{array}{l}\text { Hypothesis 2: } \\
\text { Work - family } \\
\text { conflict is } \\
\text { positively } \\
\text { correlated to } \\
\text { burnout } \\
\text { syndrome among } \\
\text { medical } \\
\text { professionals } \\
\text { practicing at } \\
\text { CSTH }\end{array}$ & Marital status (Question 1) & - & + & - & + & $\begin{array}{l}\text { Since D.P. } \\
\text { dimension and } \\
\text { total score are } \\
\text { positive this } \\
\text { finding is } \\
\text { significant. }\end{array}$ \\
\hline $\begin{array}{l}\text { Hypothesis } 3 \text { : } \\
\text { Work family } \\
\text { conflict is } \\
\text { positively }\end{array}$ & $\begin{array}{l}\text { Having less time to spend with } \\
\text { family and friends (Question } \\
\text { 13.3) }\end{array}$ & + & - & - & - & $\begin{array}{l}\text { Since E.E. } \\
\text { dimension is } \\
\text { positive this } \\
\text { finding is }\end{array}$ \\
\hline
\end{tabular}




\begin{tabular}{|c|c|c|c|c|c|c|}
\hline $\begin{array}{l}\text { correlated to the } \\
\text { emotional } \\
\text { exhaustion } \\
\text { dimension of } \\
\text { burnout } \\
\text { syndrome }\end{array}$ & & & & & & significant. \\
\hline $\begin{array}{l}\text { Hypothesis } 4 \text { : } \\
\text { Female medical } \\
\text { professionals are } \\
\text { more likely to } \\
\text { experience } \\
\text { burnout } \\
\text { syndrome than } \\
\text { males. }\end{array}$ & $\begin{array}{l}\text { Relationship between gender and } \\
\text { associated burnout syndrome } \\
\text { among the sample (Question 2) }\end{array}$ & - & - & - & - & $\begin{array}{l}\text { Finding is not } \\
\text { significant. }\end{array}$ \\
\hline $\begin{array}{l}\text { Hypothesis 5: In } \\
\text { adequate } \\
\text { resources and } \\
\text { unfriendly } \\
\text { relationships } \\
\text { which results in } \\
\text { unpleasant work } \\
\text { has a positive } \\
\text { effect on burnout } \\
\text { syndrome among } \\
\text { medical } \\
\text { professionals. }\end{array}$ & $\begin{array}{l}\text { Unpleasant work environment } \\
\text { (Question 13.4) } \\
\text { Unfriendly relationships with } \\
\text { colleagues (Question 13.6) }\end{array}$ & - & + & - & + & $\begin{array}{l}\text { Since D.P } \\
\text { dimension and } \\
\text { total score are } \\
\text { positive this } \\
\text { finding is } \\
\text { significant. } \\
\text { Since D.P } \\
\text { dimension is } \\
\text { positive this } \\
\text { finding is } \\
\text { significant. }\end{array}$ \\
\hline $\begin{array}{l}\text { Hypothesis 6: } \\
\text { Lack of } \\
\text { autonomy/contro } \\
1 \text { at work is } \\
\text { positively related } \\
\text { to burnout } \\
\text { syndrome }\end{array}$ & $\begin{array}{l}\text { Having low control/ autonomy at } \\
\text { work (13.5) }\end{array}$ & + & - & - & - & $\begin{array}{l}\text { Since E.E } \\
\text { dimension is } \\
\text { positive this } \\
\text { finding is } \\
\text { significant. }\end{array}$ \\
\hline
\end{tabular}




\begin{tabular}{|l|l|l|l|l|l|l|}
\hline $\begin{array}{l}\text { Hypothesis 7: } \\
\text { High personal } \\
\text { contact nature of } \\
\text { the job correlates } \\
\text { positively with } \\
\text { burnout } \\
\text { syndrome }\end{array}$ & $\begin{array}{l}\text { Difficult interactions with } \\
\text { patients (Question 13.8) }\end{array}$ & - & - & - & - & $\begin{array}{l}\text { This finding is not } \\
\text { significant. }\end{array}$ \\
\hline $\begin{array}{l}\text { Hypothesis 8: } \\
\text { Risk of major } \\
\text { failures on duty } \\
\text { and/or patient } \\
\text { death correlates } \\
\text { positively } \\
\text { towards burnout } \\
\text { syndrome }\end{array}$ & $\begin{array}{l}\text { Risk of having major failures of } \\
\text { duty and patient death and its } \\
\text { effects on burnout syndrome }\end{array}$ & + & + & - & + & $\begin{array}{l}\text { Since E.E, D.P } \\
\text { dimensions and } \\
\text { total score are } \\
\text { positive this } \\
\text { finding is } \\
\text { significant. }\end{array}$ \\
\hline
\end{tabular}

Refer to Table 8. A significant positive correlation between the causative factors of heavy workload and long work hours on the E. E dimension of the syndrome was evident in this research. This finding falls in line with the work of Ozge and Mahmut (2013) who established a clear link between E.E dimension and workload/ work hours. Other researchers have also found a positive correlation between burnout syndrome and workload among intensive care medical professionals (Embriaco et al., 2007). However contradictory findings are evident where an association between physical workload and E.E was not found among medical professionals (Aguir, Baena\& Perez - Hoyos, 2005).It was found by this study that engagement in private practice/ other income generating activities had no association with any dimension (EE/DP/PA) of the syndrome. However in the present study it is established that workload and work hours are positively correlated and as a possible cause for burnout syndrome, thus we can accept hypothesis 1: 'Higher number of working hours and heavy work load is positively correlated to burnout syndrome among medical professionals practicing at CSTH'.

In terms of work family conflict as a causative factor of burnout syndrome, it was observed that marital status was positively correlated to overall burnout syndrome (E.E/D.P/P.A) and in particular with the DP dimension. This finding confirms the results of Halpern (2005), where meeting family obligations and work demands has caused mental strain among medical professionals, thus tallying with the other research where more married individuals were identified to be prone to the syndrome than the others. Having less time to spend with family and friends particularly due to the interference with work, correlated positively with the E.E dimension of the syndrome, thus confirming the pre - formed Hypothesis 2: Work - family conflict is positively correlated to burnout syndrome among medical professionals practicing at CSTH and Hypothesis 3: Work family conflict is positively correlated to the emotional exhaustion dimension of burnout syndrome .Furthermore this result conformed to the findings of 
Karatepe and Tekinkus (2006), where work family conflict was identified as a causative factor of E.E dimension of the syndrome.

There was no significant relationship established between the gender and any of the dimensions of the syndrome. Therefore the pre - formed hypothesis, 'female medical professionals are more likely to experience burnout syndrome than males' is void; cannot be accepted. Current finding falls in line with the work of Erdur et al., (2006), who also could not establish a relationship between gender and burnout syndrome. Contrastingly other scholars have established causal relationships where female physicians were more burned out than their male counter parts (Embriaco et al., 2007). This was not the case in Sri Lanka possibly suggesting that dual career households have increased over the years where both males and females are likely to share responsibility to complete family related chores.

It was evident from the findings that unpleasant work environments positively correlated with the burnout syndrome in all three dimensions in combination (EE/DP/PA) and in particular DP dimension. The current study results confirm the findings of Maslach, Shaufeli \& Lieter (2001) who also established a causal relationship between inadequate resources to provide patient care, which result in unpleasant work environments and Burnout Syndrome among medical professionals. Embriaco et al., (2006) also state that inadequate resources in the intensive care units have caused burnout syndrome among many medical professionals. According to Carod Artal \& Vasquez Cabrera (2013) developing countries are constantly battling with inadequate resources to perform the ever increasing patient care. This could be particularly true for countries such as Sri Lanka, where government spending is limited and the medical professionals are performing under pressure to supply the high demand with limited hospital resources. Other comments of the survey mentioned by medical professionals proved this where responses such as malfunctioning of equipment, lack of facilities, inadequate resources, lack of basic facilities, not having an on call room, and inadequate room to work. All such responses indicate the unpleasant work environments depicted by the lack of resources to perform patient care at CSTH. Another predictor of unpleasant work environments was unfriendly relationships with colleagues which in fact had a positive correlation with the DP dimension of the syndrome. In adequate resources coupled with lack of support from co - workers and unfriendly relationships fostered have resulted in burnout syndrome in the current study. The findings of the study tally with the findings of Maslach, Shaufeli \& Leiter (2001), where lack of support and unfriendly relationships were seen as correlates of the burnout syndrome. Therefore it is possible to say from the findings that the hypothesis 5: 'in adequate resources which result in unpleasant work have a positive influence on burnout syndrome among medical professionals' could be accepted.

From the current findings it is possible to say that lack of autonomy/control at work positively correlated with the EE dimension of the syndrome. This confirms the research of Spickard, Gabbe and Christensen (2009), who stated that lack of control over work resulted in the occurrence of burnout syndrome. According to Freeborn (2001) most important predictor of the syndrome among physicians was low autonomy/ control at work. Therefore it is possible to conclude that the pre formed 'hypothesis 6: Lack of autonomy/control at work is positively related to Burnout syndrome' from the present findings is accepted. Contradictory findings are reported where certain scholars could not establish a relationship between low control/autonomy at work and Burnout syndrome. However in the local context lack of autonomy/control did appear to be a causative factor of the syndrome. 
Difficult interactions with patients which lead to high personal contact nature of the job have been regarded as a causative factor of burnout syndrome (Maslach, Shaufeli \& Leiter, 2001). According to the finding of the present study, high contact nature of the job did not have a positive relationship with the burnout syndrome among medical professionals practicing at $\mathrm{CSTH}$. This funding is controversial with established literature where the pre formed hypothesis 7: 'high personal contact nature of the job correlates positively with burnout syndrome' is rejected.

Most literature on burnout syndrome highlights the risk of major failure and/or patient death as a main antecedent of the syndrome (De Valk \& Oostrom, 2007). From the present study findings it is possible to say that risk of major duty failure and/or patient death appears to positively correlate with burnout syndrome, particularly in E.E and D.P dimensions. This finding is agreeable with the research of Meier, Back and Morrison (2007) where evidence of physicians being emotionally being attached to patients suffering from serious illness was observed. Similarly Chlan and Linda (2013) stated that constant life and death struggles of patients created an emotional turmoil for the medical professionals who treated the deceased. Therefore it is possible to establish from the current findings that hypothesis 8: 'risk of major failures on duty and/or patient death has a positive association with burnout syndrome' is true among medical professionals practicing at the CSTH.

\section{Coping strategies currently practiced by medical professionals}

Majority of the medical officers frequently practiced listening to music to reduce stress (29\%) followed by getting emotional support from friends/ colleagues (24\%) and thereafter tried to find comfort in religion or spiritual belief $(21 \%)$. Of the study sample, $31 \%$ of medical officers never tried to reduce stress by physical exercise, which provides implications for CSTH to promote exercise and fitness to alleviate burnout syndrome. Similar studies on IT professionals it was reported that more frequently used coping strategies were harmless emotion focused strategies (Wijerathna, 2006). Furthermore findings indicate that most frequently practiced coping strategies were problem focused which reached $55 \%$ of respondents who tried to get support from relevant people and worked accordingly. A further $60 \%$ of respondents engaged moderately in emotional harmless coping strategies.

The present study revealed that majority of medical officers never practiced the harmful coping strategy of taking alcohol or other substances to find comfort in the stressful situation (92\%). However it was noted that a high of $57 \%$ engaged sometimes in emotional harmful coping strategy where the respondents tried to keep all feelings to themselves without expressing and blaming themselves. Even though this occurrence was on the scale of 'sometimes' and not frequently this provides the CSTH management to increase support for medical professionals to deal with stressful situations. In the study on IT professionals seven percent of the participants frequently consumed alcohol (Wijerathna, 2006), whereas this was not the case in the case of CSTH medical professionals. However the current findings contradicted with the research of Chlan and Linda (2013) who reported that alcohol and substance use was positively related with burnout syndrome. The proportion of charted accountants who practiced harmful emotional stress coping strategies often was 1.3\% (Nanayakkara, 2003) in Sri Lanka. According to this study cognitive emotion focused coping strategies were mostly moderately practiced by the medical officers in CSTH, where around $84 \%$ sometimes engaged in these strategies. 
Figure 2: Burnout syndrome, its associated causes and coping strategies framework

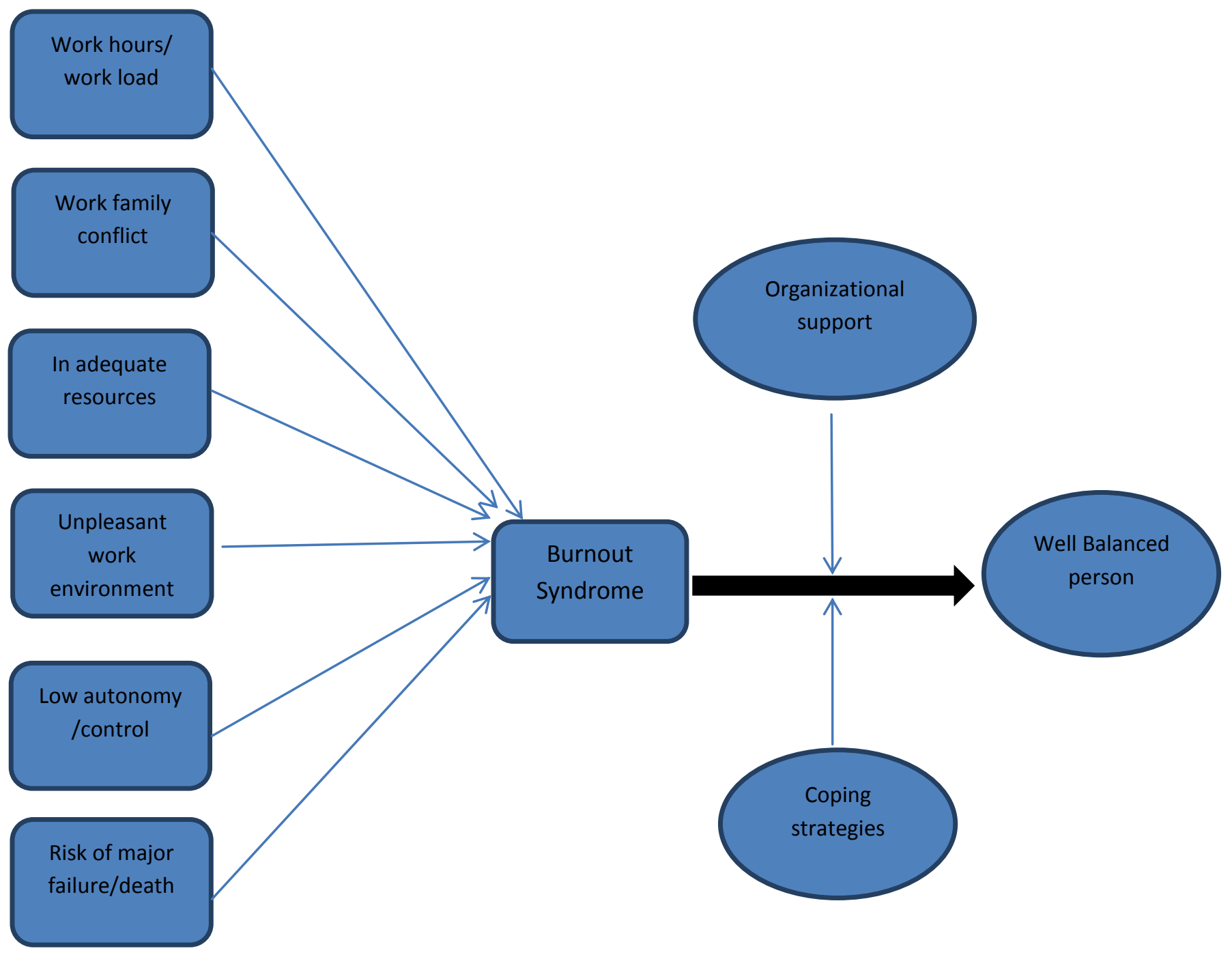

According to the findings the above framework was developed by the authors, where the accepted hypotheses were used to identify the underlying causes of the burnout syndrome. Thereafter the organizational support in terms of providing adequate resources and psychological support for individuals is identified as a factor that can reduce the occurrence of the syndrome along with emotional harmless, problem focused and cognitive coping strategies.

\section{Conclusion}

Using the sample of responses obtained from CSTH the primary objectives of the study were fulfilled by identifying the prevalence of the syndrome as 53\%. Furthermore it was identified that among the sample an appalling figure of individuals suffering from the syndrome on each 
dimension as follows that E.E dimension exists among $30 \%$ of medical professionals, D.P dimension among $24 \%$ and P.A dimension in $85 \%$. The underlying causes of the syndrome were hypothesized after analyzing the key theoretical underpinnings of the literature. These hypotheses were then tested to identify the key predictors of burnout syndrome in the local context as long work hours/ work load, work family conflict, inadequate resources provided by the hospital, unpleasant work environments, low autonomy/control and risk of major duty failure and/or patient death. Study did not establish a correlation between the syndrome and engagement in private practice, gender and difficult interactions with patients. When considering the coping strategies practiced by medical professionals it was evident that frequently practiced coping strategies for stressful situations are listening to music (29\%), getting emotional support from family and friends (24\%), and seeking comfort in religion or spiritual belief (21\%). It was also illustrated that $31 \%$ of medical professionals never tried to reduce stress by physical exercise. Furthermore on a very positive note the present study revealed that majority of medical officers never practiced the harmful stress coping strategy of taking alcohol or other substances to find comfort in the situation $(92 \%)$.

\section{References}

Aguir, V. E, Baena, D.M and Perez - Hoyos,S (2006) Psychosocial work environment and burnout among emergency medical nursing staff, International Archives of Occupational and Environmental Health, Vol. 80, pp.127 - 133.

Alwis, D and Christopher, C (2014) The state of Sri Lanka's healthcare, The Sunday Leader, (29November), available http://www.thesundayleader.lk/2012/11/10/the-state-of-srilankas-healthcare [Accessed 28th November 2014]

Baldwin P.J, Dodd M and Wrate R. W. (1997), Young doctor's health: I. How do working conditions affect attitudes, health and performance?, Social Science \& Medicine, Vol.45, No.1, pp. $35-40$.

Barbosa, F.T,Leão B.A, Tavares ,G.M and Santos, J.G. (2012), Burnout syndrome and weekly workload of on-call physicians: cross-sectional study, Sao Paulo Medical Journal. , Vol. 130, No. 5, pp. 282-288.

Bond, F.W and Bunce, D. (2000) Mediators of change in Emotion - focused and problem focused worksite stress management interventions, Journal of Occupational Health Psychology, Vol. 5, No.1, 156 - 163.

Braunstein-Bercovitz, H. (2013), A multidimensional mediating model of perceived resource gain, work-family conflict sources, and burnout, International Journal of Stress Management, Vol. 20, No. 2, pp. 95-115.

Bruce, M. (2004), Physician burnout: a pilot study, New Zealand Medical Student Journal, Vol. 1, pp. $14-19$.

Burke, R, Koyuncu, M, and Firsenbaum, L .(2008), Gender differences in work experiences, satisfactions and wellbeing among physicians in Turkey, Gender In Management An International Journal, Vol. 24, No. 2, pp. 70 - 91.

Byrne B.M. (1994), Burnout: testing for the validity, replication, and invariance of causal structure across elementary, intermediate, and secondary teachers, American Educational Research Journal, Vol. 31, pp. 645-673.

Carod - Artal, F.J. and Vasquez - Cabrera,C.(2013), Burnout syndrome in an international setting, Rev Med InstMexSequro Social Journal Articles ;43:11-5.[Pub Med]. 
Carter, A. J. and West, M.A. (1999), Sharing the burden - team work in health care settings. Stress in Health Professionals: Psychological and Organizational Causes and Interventions, pp. $191-202$.

Chlan, R.N, and Linda, L.(2013), Burnout Syndrome Among Critical Care professionals: A Cause for Alarm, Critical Care, Jessica Kingsley Publishers.

De Valk,M and Oostrom, C.(2007), Burnout in the medical profession, causes, consequences and solutions, Occupational Health at Work, Vol. 3, No. 6, pp. $354-367$.

DeValk, M.A. and Werner, A. (2000), Burnout in medical professionals: a cost-effectiveness study of a multidisciplinary intervention program, Occupational Medicine, Vol. 50, pp. 289-93.

Diez - Pinol, M, Dolan, S. L, Sierra, V and Cannings, K. (2007), Personal and organizational determinants at work: case of Swedish physicians, International Journal of Healthcare Quality Assurance, Vol. 21, No. 6, pp. 598 - 610.

Dolan, S.L., Garcia, S. and Auerbach, A. (2003), Understanding and managing chaos in organizations, International Journal of Management, Vol. 20, No. 1, pp. 23-36.

Ellahi, A, and Mashtaq,R.(2012), Doctors at risk of job burnout, diminishing performance and smoking habits, A Journal of The BSA Medical Sociology Group, Vol. 6, No. 3, pp. 36 47.

Ellawala, Y. (2010), Psychological distress, associated factors and coping strategies among female student nurses in the nursing training school Galle. MSc thesis. Postgraduate institute of medicine Sri Lanka.

Embriaco, N, Azoulay, E. Barrau, K., Kentish,N., Pochard,F.,Londou,A, and Papazian, L. (2007), High level of burnout in intensivits; prevalence and associated factors, American Journal of Respiratory and Critical Care Medicine, Vol. 175, No. 11, pp. 1209 - 1210.

Erdur, B. Ergin, A. Turckuer, I, Parlak, I, Ergin, N and Boz, G.(2006), A study of depression and anxiety among doctors working in emergency units in Denizil, Turkey, Emergency Medicine Journal, Vol. 23, pp. 759-763.

Evans, W. and Kelly, B.(2004), Pre-registration diploma student nurse stress and coping measures, Nurses Education Toda, May 17,(24;6), pp. 473-482.

Farber, B.A. (2000), Burnout in Psychotherapist: Incidence, types, and trends. Psychotherapy in Private Practice, Vol. 8, pp. 35 - 44.

Firth - Cozens, J. (2007), Improving the health of psychiatrists, Advances in Psychiatric Treatments, Vol. 13, pp. 161 - 168.

Firth-Cozens, J. (1998), Individual and organizational predictors of depression in general practitioners. British Journal of General Practice, Vol. 48, pp. 1647-1651.

Freeborn, D.K. (2001), Satisfaction, commitment, and psychological well-being among HMO physicians, Western Journal of Medicine, Vol. 174, No. 1, pp. 13-18.

Greene G. 1991. A Burnt-out Case. New York: Viking Press.

Greenhaus, J. H, and Beutell, N. J. (1985), Sources of conflict between work and family roles. The Academy of Management Review, Vol. 10, pp. 76-88.

Gunawardhana, A. (2014), Burnout syndrome among medical professionals. (in person interview).

Hakanen, J.J. and Schaufeli, W.B.(2012), Does burnout and work engagement predict depressive symptoms and life satisfaction? A three wave seven year prospective study, Journal of Affective Disorders, Vol. 24, pp. 415-424. 
Halpern, D. F. (2005), How time-flexible work policies can reduce stress, improve health, and save time. Stress and Health, Vol. 21, pp. 157-168. doi:10.1002/smi.1049

Karatepe, M. O. and Tekinkus, M. (2006), the effects of work-family conflict, emotional exhaustion and intrinsic motivation on job outcomes of front-line employees. International Journal of Bank Marketing, Vol. 24, pp. 173-193.

Kinzl, J. F, Traweger, C, Biebl, W. and Lederer, W. (2006), Burnout and stress disorders in intensive care doctors, Deutsche MedizinischeWochenschrift, Vol. 131, pp. 2461-2464. [PubMed].

Lazarus, R. S and Folkman, S (1984) Stress, appraisal and coping. New York: Springer.

Lee, F. J, Stewart, M and Brown, J. B. (2008), Stress, burnout, and strategies for reducing them, Canadian Family Physician, Vol. 54, pp. $234-235$.

Lee,R.T, and Ashforth, B.E.(1993), A longitudinal study of burnout among supervisors and managers: Comparisons between the Leiter and Maslach(1988) and Golenbiewski et al (1986) models, Organizational Behaviour and Human Decision Processes, Vol. 54, No. 3, pp. 369-398.

Linzer, M, Visser, M. R. M, Oort, F. J, Smets, E. M. A, Mc Murray, J. E and De Haes, H.C.J.M. (2001), Predicting and preventing physician burnout: results from the United States and Netherlands.

Maslach C. (1982), Burnout: The Cost of Caring. Englewood Cliffs, New Jersey: Prentice-Hall.

Maslach, C .(1976), Burned - out, Human Behavior, Vol. 9, pp. 16 -22.

Maslach, C, and Jackson S, E. (1981), The measurement of experienced burnout, Journal of Occupational Behaviour, Vol. 2, pp. $99-113$.

Maslach, C, Jackson, S.C, and Leiter, M.P (1996), Maslach burnout inventory, Palo Alto Califonia: Consulting Psychologists Press.

Maslach,C., Schaufeli, W.B. and Leiter, M.P.(2001), Job Burnout, Annual Review of Psychology, Vol. 52, pp. 397-422.

Meier, D.E, Back, A.L. and Morrison, R.S. (2007), The patient- physician Relationship - The inner life of physicians and care of the seriously ill', Public Environmental \& Occupational Health, Vol. 28, No. 7, pp. 3007-3014.

Montero - Marin, J. \& Garcia - Campayo, J.(2010), A newer and broader definition of burnout: validation of the 'Burnout Clinical Subtype Questionare (BCSQ-36)', BMC public health, October, 302.

Montgomery, A, Panagopoulou, E, Kehoe, I and Valkanos, E. (2010), Connecting organizational culture and quality of care in the hospital: is job burnout the missing link?,Journal of Health Organization and Management, Vol. 25, No. 1, pp. 108 - 123.

Nanayakkara, B.M.(2003), Selected factors associated stress and coping strategies among chartered accountants in Greater Colombo area, Sri Lanka. Dissertation (MSc in community medicine), Postgraduate Institute of Medicine, University of Colombo.

Ozge, T and Mahmut, A (2013) The role of lack of reciprocity, supervisory support, workload and work - family conflict on exhaustion: evidence from physicians, Psychology, Health \& Medicine, Vol. 18, No. 5, pp. $564-575$.

Quill,T.E and Williamson,P.R.(1990), Healthy Approaches to Physician Stress, Journal of the American Medical Association, Vol. 150, No. 9, pp.1857 - 1861.

Roth, M, Morrone, K, Moody, K, Kim, M, Wang, D, Moadel, A. and Levy, A. (2011), Career burnout among pediatric oncologists. Pediatric Blood \& Cancer, Vol. 57, pp. 1168-1173. 
Samaranayake, D. B. D. L and SeneviratneS.R.D.A. (2012), Validity of the Maslach Burnout Inventory - Human Services Survey among Sri Lankan Nursing Officers, Psychological Studies, Vol. 57, No. 1, pp. $101-111$.

Samuel M.Y.Ho, and Rosalie S.Y.Lo (2011), Depositional Hopes as a Protective Factor Among Medical Emergency Professionals: a Preliminary Investigation, Traumatology, Vol. 17, No. 4, pp. $3-9$.

Shanafelt, T. D., West, C., Zhao, X., Novotny, P, Kolars, J, Habermann, T. and Sloan, J. (2005), Relationship between increased personal well-being and enhanced empathy among internal medicine residents. Journal of General Internal Medicine, Vol. 20, No. 7, pp. 559-564.

Sharma, A, Sharp, D. M, Walker, L. G, and Monson J. R. (2008), Stress and burnout in colorectal and vascular surgical consultants working in the UK national health service, Psycho Oncology. Vol. 17, pp. 570- 576.

Shirom A. (1989), Burnout in work organizations. International Review of Industrial and Organizational Psychology, ed. CL Cooper, I Robertson, New York: Wiley, pp. 25-48.

Spickard A, Gabbe S.G, and Christensen J.F. (2009) Mid-career burnout in generalist and specialist physicians. Journal of American Medical Association, Vol. 288, No. 12, pp. 1447 - 1450 .

USJ (2012), Colombo South Teaching Hospital [online]. Available from: http://www.medical.sjp.ac.lk/index.php/teaching-hospital-csth [On 31st April 2014].

Weinberg, A. \& Creed, F. (2000), Stress and psychiatric disorder in healthcare professionals and hospital staff. Lancet, Vol. 355, No. 9203, pp. 533-537.

Wijeratne, M.(2006), Prevalence of psychological distress, factors associated with work stress and coping strategies adapted by Information technology professionals. Dissertation (MSc in community Medicine), Postgraduate Institute of Medicine, University of Colombo.

Wu, S., Zhu, W., Li, H., Wang, Z. and Wang, M. (2008), Relationship between job burnout and occupational stress among doctors in China. Stress \& Health, 24: 143-149. doi: 10.1002/smi.1169

Zapf, D., Seifert, C., Schmutte, B., Mertini, H. and Holz, M. (2001) Emotion work and job stressors and their effects on burnout, Psychology \& health, Vol. 16, No. 5, pp. 527 545. 